\title{
The Possible Impact of Problem-solving Method of Instruction on Exceptional Students' Creativity
}

\author{
Adnan Eshrati Fard ${ }^{1}$, Ali Bahador ${ }^{2}$, Mahsa Nazemi Moghadam ${ }^{1}$, Hooman Rajabi ${ }^{3}$, Ali Noor Moradi ${ }^{4}$ \\ ${ }^{1}$ Department of Education psychology, Kharazmi University, Tehran, Iran \\ ${ }^{2}$ Department of Clinical Psychology, Islamic Azad University, Kerman, Iran \\ ${ }^{3}$ Department of Education Psychology, Tehran University, Tehran, Iran \\ ${ }^{4}$ Department of Education Psychology, Islamic Azad University, Save, Iran \\ Correspondence: Adnan Eshrati Fard, Department of Education Psychology, Kharazmi University, Tehran, Iran
}

\author{
Received: February 10, $2014 \quad$ Accepted: March 1, $2014 \quad$ Online Published: May 8, 2014 \\ doi:10.11114/jets.v2i3.342 URL: http://dx.doi.org/10.11114/jets.v2i3.342
}

\begin{abstract}
The current study aimed at investigating the possible impact of the problem-solving method of instruction on the exceptional students' creativity. A sample of 50 male exceptional (Mild intellectual disability) students studying in the third grade of junior high school was chosen and divided into two equal groups. Both groups filled out the Torrance Test of Creative Thinking (TTCT) in pre- and post-test stages. They also completed the Raven Standard Progressive Matrices (RSPM) as a covariate variable. The results of covariance analysis revealed that the mean value for creativity score was higher for the students provided with the problem-solving method of instruction than that of their counterparts provided with the traditional method of instruction while the effect of intelligence was controlled. The scores obtained for the factors including fluency, flexibility, originality, and elaboration also increased through problem-solving method of instruction.
\end{abstract}

Keywords: creativity, problem-solving method of instruction, traditional method of instruction, exceptional students

\section{Introduction}

Creativity as a complicated and challenging concept is unique with regard to its definition and relevant reliable viewpoints. Having more than one hundred definitions in different fields indicates the complexity of the concept (Jackson et al., 2012) According to Oxford Advanced Dictionary, it is defined as "thinking about problems through innovative ways and ideas" (Fatemi, Hamidi, \& Rahimi, 2011). Guilford refers to it as a type of divergent thinking in problem-solving which entails fluency, flexibility, originality and elaboration (Eshrati Fard, Asgary, Sarami, \& Zarekar, 2014). Fluency means creating several thoughts simultaneously, (i.e., a person can present a large number of solutions in a short time). It puts emphasis not on the innovative and unusual solutions but on the number of them (Fatemi, Hamidi, \& Rahimi, 2011). Flexibility refers to the creation of various ideas and unusual solutions to solve a problem. It puts more emphasis on the unusual quality of the solution. An individual who enjoys this characteristic more provides the type of solutions which may not occur to the others' minds (Stojanovaa, 2010). Originality means new solutions and highlights the innovation of the solutions while they may not be unusual (Fatemi, Hamidi, \& Rahimi, 2011). Elaboration means the creation of details and the way they are interpreted. It allocates more attention to details in both posing the problem and presenting the solutions. An individual who enjoys this characteristic presents the solutions for all details through attending to and analyzing them (Stojanovaa, 2010).

Creativity has received considerable attention especially in developed countries over the past few decades. It has resulted from the technological-scientific revolution which clearly indicated that a creative mind would hopefully lead to a general development in all domains of life (Stojanovaa, 2010). On the other hand, in spite of severe economic and social crises, societies require new innovations which necessitate active searching for identifying methods in order to increase creativity (Tennyson \& Breuer, 2002).

A number of studies have so far focused on identifying the factors contributing to an increase in creativity. One set of studies (e.g., Batey, Furnham, \& Safiullina, 2010; Furnham et al., 2008; Furnham \& Bachtiar, 2008) have dealt with the role of personal characteristics. A second set of studies (e.g., Kletke, 2001; Barak \& Mesika, 2007; Kandemir \& Gür, 
2009) have touched upon the role of environmental factors especially educational organization in the process of creativity. Educational organization is one of the most important one which plays a vital role in creativity and its main duty is to develop the students' creativity and the way its instruction can penetrate into schools. However, among the current systems of education, it is the traditional instruction rather than the creative one which is commonly used (Prsaud, 2007) Researchers mostly believe that the traditional instruction which emphasizes on teaching through giving lectures, not only does not contribute to the development of creativity among children but also impeded their progress. In this sense, the class time is mostly spent taking and the students do not play an active role in the learning process which consequently results in their lack of motivation in classrooms (Johnson, Aragon, \& Shaik, 2000) Although the traditional method of instruction or the lecture-based method lead to inactivity, lack of attention to free thinking, problem-solving, and creative thinking among most of the students, this is more highlighted among exceptional students due to their specific problems. This group of students has lower degrees of intelligence and compatibility compared with their ordinary counterparts. Students are divided into different groups including blind, deaf, Learning disabilities, and Intellectual disability students (Anne, 2002). Providing these students with instruction should build up their motivation, increase their cooperation, make learning more attractive for them and even more importantly, enhance their abstract and creative thinking through taking their mental problems into account (Geoffrey \& Ilanit, 2007). This seems impossible taking a traditional approach to teaching (Kyaga et al., 2013).

Moreover, a number of scholars have demonstrated that although the extent of creativity among these students is lower than that of their ordinary counterparts, it can be enhanced (Geoffrey \& Ilanit, 2007). This will not only improve their learning but also help them in other life aspects while confronting with problems by using more creative ways (Geoffrey \& Ilanit, 2007).

There are a wide range of techniques and skills contributing to an increase in creativity. Some of the main ones encompass brainstorming, Cynectics, obligatory communication, cooperative learning, adjectives, and problem-solving (Samkhanian, 2008). These techniques reiterate the active role of the learner, an increase in self-confidence, and production of several ideas by the institutes (Barak, Mesika, 2007). Problem-solving skill seems to be more useful than the others since the ideas are presented considering both systematic and goal-oriented criteria. Accordingly, the number of ineffective solutions decreases (Samkhanian, 2008).

Problem-solving is a method comprising of several goal-oriented stages and is of great use in solving personal individual problems (Armagan, Sagır, \& Çelik, 2009). Exceptional students who acquire this skill can hopefully be successful in each and every stage of their life, even in confronting with the problems they have not faced yet. By applying this skill, Exceptional students will learn how to exploit various innovative solutions while facing a problem. Hence, considering the fact that these students are confronted with numerous problems in their life, employing this method of instruction would be of great help (Adams \& Stoneham, 2009).

A number of researchers maintain that instruction through problem-solving method would result in enhancing the students' creative and abstract thinking, highlighting their innovative and unusual solutions, helping them to play an active role in the learning process, and enhancing their motivation (Guilford, 1977; Runco, 2007; Treffinger, Selby, \& Isaksen, 2008) In this regard, a host of studies have been conducted. For instance, Torrance investigated the junior high school and high school students' creativity and found that the most successful method for developing the students' creativity was problem-solving skill (Kandemir \& Gür, 2009). In another study, Helfman (1992) investigated the influence of problem-solving method of instruction on creative planning of the projects in Physics. The results revealed the superiority of this method over the traditional one (Barak \& Mesika, 2007). Mumford (2001) also found out that the participants who were taught through problem-solving method made use of various, innovative solutions while answering the questions.

Although a number of studies explored the possible impact of problem-solving method of instruction on creativity, all have been focused on the ordinary students. No study has been conducted or reported taking the exceptional students into account. Hence, investigating this issue seems to be of utmost significance.

On the other hand, even in the studies conducted on the ordinary students, it seems that scant attention has been allocated to a number of factors which may make an impact on creativity. In this sense, one of the main research questions is whether an increase in creativity, in these studies (Barak \& Mesika, 2007; Kandemir \& Gür, 2009) was achieved necessarily as a result of the problem-solving method of instruction or some other factors also contributed to it. Some scholars (Batey, Furnham, \& Safiullina, 2010; Furnham et al., 2008) believe that the most appropriate method to examine creativity is the one which simultaneously takes the role of several factors into consideration. In this regard, it seems that personal characteristics, knowledge, motivation, intelligence, and gender made the most obvious impact (Furnham et al., 2008).

Intelligence as a crucial variable influences creativity. In other words, intelligence closely correlates with different 
aspects of creativity and a minimum degree of it is necessary for creativity (Furnham \& Bachtiar, 2008). In other words, an increase in intelligence would lead to an increase in creation up to a certain extent. For IQ scores higher than 130, it seems that it has no significant influence on creativity (Furnham et al., 2008). Considering the fact that the students with mild intellectual disability have IQ levels less than 70, this would influence their creativity more and thereby, those with higher IQ would be more creative (Geoffrey \& Ilanit, 2007) Taking together, the role of IQ as a covariate which might influence these students' creativity was controlled in this study in order to avoid its possible impact on the teaching process. On the other hand, the role of the students' gender, which makes an important impact on the relationship between the type of instruction and creativity, has received scant attention. For instance, girls pay more attention to details while boys favor generalities (Conti, Collins, \& Picariello, 2001). Hence, considering the impact of intelligence and gender on the relationship between the method of instruction and creativity, the current study strived to obtain more precise results through controlling these two variables.

Bearing this in mind, the study primarily aimed to investigate the influence of problem-solving method of instruction on the students with mild intellectual disability. It further took all components of creativity into account and strived to explore the possible influence of this method on them. The study specifically addressed the following two questions:

1. Does problem-solving method of instruction result in an increase in the exceptional students' creativity?

2. How will the problem-solving method of instruction influence the creativity factors (fluency, flexibility, originality, and elaboration)?

\section{Methods}

\subsection{Participants}

The sample consisted of 50 exceptional (Mild intellectual disability) students who were studying in the third grade of junior high school with the average age of 18.5 years old and was divided into two groups. Out of all the male students with mild intellectual disability in the third grade in Tehran (the capital of Iran), 50 ones were randomly selected and assigned to two groups of equal size ( 25 ones in each group).Taking into account the influence of gender on creativity and the type of instruction, only male students were included in the sample.

\subsection{Instruments}

\subsubsection{Torrance Test of Creative Thinking (TTCT)}

The questionnaire was devised by Torrance (1974) underlying Guilford Intelligence theory. Torrance designed a series of tests for creativity including two verbal tests (parallel forms of A \& B) and two pictorial tests (parallel forms of A \& B) (Seif, 2008). In the study, the B form of pictorial test for adults (over 12 years old) was utilized. The test can be administered both individually and cooperatively. It includes three activities which take almost 30 minutes (10 minutes for each activity). According to technical guide and scoring style of Torrance (Torrance, 1974). in pictorial form, like the verbal one, no emphasis is put on misspelling, shortage of vocabulary in evaluation and drawing skill. The criterion for evaluation is the presence of creative ideas in the form of a picture rather than the quality of the drawing. Hence, the presence of every individual sign which indicates creative thinking is considered in evaluation. As a result, even if the person enjoys a scant degree of drawing skill, person can perform moderately or well in the pictorial form. At the end of each activity, the person is asked to determine a title or to develop a story for drawing in order to better clarify the pictorial idea. Torrance (Torrance,1990) obtained the test-retest reliability of 0.88 to 0.96 . The reliability index for th test in this study was calculated through Cronbach alpha as 0.87 . The validity of this test was also approved by the expert judgments.

\subsubsection{Raven Standard Progressive Matrices (RSPM)}

This test was designed by Raven (1958) and is considered as one of the most popular and applicable tests of intelligence which is utilized to measure people's general IQ. There are a host of reasons for this test being popular: it is easy to be administered, it can be administered both individually and cooperatively, it is culture-independent, and applicable for all age groups (Pind, 2003). This test includes 60 pictures, one part of each is missing and the test should find the missing part among six or eight different alternatives. The test items are divided into five groups so that each of them includes 12 items whose difficulty level is gradually increasing (Schweizer, Goldhammer. Rauch, \& Moosbrugger, 2007). It takes 45 minutes and for each correct picture, one point is assigned. The maximum score for each test will be 60 . Then, taking the raw score and the age of the test into account, the equivalent intelligence score in table is determined. Barak obtained the Cronbach reliability coefficient of 0.96 for the RSPM (Williams \& Mccord, 2006). In the current study, the reliability coefficient was 0.89 .

\subsubsection{Polya's Pattern of Problem-solving Method of Instruction}

In order to teach through problem-solving method of instruction, Polya's (1957) pattern was used. This pattern includes 
four phases including: 1. understanding the problem: which is conceived of as the stage of knowing and perceiving the concepts and requirements of the problem. Drawing the learners' attention to the problem, defining it, elaborating on the key words, stating the problem simply by the learners are among the techniques which are employed in this phase (Santrock, 2011), 2. planning for the problem: which means planning for implementing and selecting the practical solutions for solving the problem. In this stage, however, the problem is not solved; but a number of plans are presented among which the best one is selected (Barak \& Mesika, 2007), 3. implementing the plan and selected solutions: which comes after selecting various solutions and achieving the students' consensus. The students implement them individually and report their progress to the group. The members of each group then discuss the ideas and report the results (Santrock, 2011), 4. revising and controlling the problem: all the implemented methods are compared and their probable flaws are removed (Barak \& Mesika, 2007), In this study, the math book of the third grade was taught taking this pattern as well as the educational objectives into consideration.

\subsection{Procedure}

Before presenting the lessons, in order to measure the students' primary creativity and IQ scores, the pictorial form of Torrance's Test of Creative Thinking (Form B) (Torrance, 1974) and Raven's IQ test (Raven ,1958) were administered by the researchers, respectively. Then, math instruction was provided through problem-solving method and Polya's pattern in one group while it was provided through traditional method (giving lecture) in the other group in twelve 50-minute sessions. A specific part of the math book was developed into an educational package through Polya's pattern. This package determined the content and the method of instruction for each session. All these topics were developed based on Polya's pattern and implemented in twelve 50-minute sessions. In this method, a number of educational aids (or kits) including pictures, plastic tools, etc. were utilized. In traditional method, though, the topics were mostly presented through giving lecture and making use of several educational aids, (e.g., pictures, plastic tools, etc). The researchers provided the instruction in both groups. Finally, form B of the Torrance's test was again administered. Following that, obtained data were fed into SPSS 16. In order to control for the impact of intelligence and pre-test as well as data analysis, covariance analysis was used after the examination of its underlying assumptions.

\section{Results}

Table 1 summarizes the descriptive statistics (including mean and standard deviation) for the obtained data. In order to analyze the data, covariance analysis was run. Tables 2 and 3 illustrate the results.

Table 1. Mean and standard deviation for the factors for both groups

\begin{tabular}{|c|c|c|c|c|c|c|c|c|}
\hline \multirow{3}{*}{ Resources } & \multicolumn{4}{|c|}{ Problem-solving method instruction } & \multicolumn{4}{|c|}{ Traditional method instruction } \\
\hline & \multirow{2}{*}{$\begin{array}{l}\text { Pre-test } \\
\mathrm{M}\end{array}$} & \multicolumn{2}{|c|}{ Post-test } & \multicolumn{2}{|c|}{ Pre-test } & \multicolumn{3}{|c|}{ Post-test } \\
\hline & & SD & M & SD & $\mathrm{M}$ & SD & M & SD \\
\hline Creativity & 59.24 & 4.14 & 72.22 & 5.90 & 60.32 & 4.10 & 62.21 & 4.45 \\
\hline Fluency & 6.90 & 1.93 & 8.89 & 2.08 & 7.00 & 1.98 & 7.68 & 2.02 \\
\hline Flexibility & 8.02 & 2.03 & 11.09 & 2.96 & 8.06 & 2.31 & 8.29 & 2.32 \\
\hline Originality & 8.76 & 2.11 & 11.56 & 3.01 & 8.80 & 2.43 & 8.98 & 2.44 \\
\hline Elaboration & 35.56 & 3.14 & 40.68 & 4.01 & 36.46 & 3.69 & 37.26 & 3.14 \\
\hline Intelligence & 63.04 & 4.76 & & & 62.33 & 4.45 & & \\
\hline
\end{tabular}

Note: $\mathrm{M}=$ Mean, $\mathrm{S}=$ Standard Deviation

As Table 1 displays, the mean value for the students' creativity in pre- and post-test of the group provided with problem-solving method of instruction (72.22 versus 59.24) increased about 12.98. This value was 1.99 for fluency (8.89 versus 6.90$), 3.07$ for flexibility (11.09 versus 8.02 ), 2.80 for originality (11.56 versus 8.76 ), and 5.12 for elaboration (40.68 versus 35.56 ). On the other hand, the mean value of the creativity and its factors between pre- and post-test underwent no significant increase in the group provide with traditional method of instruction. This increase in value was 1.89 for creativity (62.21 versus 60.32$), 0.68$ for fluency ( 7.68 versus 7.00$), 0.26$ for flexibility ( 8.29 versus $8.06), 0.18$ for originality ( 8.98 versus 8.80 ), and 0.80 for elaboration (37.26 versus 36.46$)$. Table 1 also demonstrates that no significant difference exists between the groups with problem-solving (63.04) and traditional (62.33) method instruction in terms of their average intelligence.

Following the descriptive statistics, the research questions were examined through covariance analysis. The following results were obtained for the first research question as follows:

1. Does problem-solving method of instruction result in an increase in the exceptional students' creativity? The results related to this question are presented in Table 2. 
Table 2. Summary of covariance analysis of the total score for creativity taking intelligence and pre-test as the control factors

\begin{tabular}{lrrrrr}
\hline Resources & SS & DF & MS & F & P-value \\
\hline Creativity Pre-test & 261.32 & 1 & 261.32 & 26.18 & .01 \\
Intelligence & 321.25 & 1 & 321.25 & 32.18 & .01 \\
Group & 792.65 & 1 & 792.65 & 79.42 & .02 \\
Error & 429.43 & 43 & 9.98 & & \\
\hline
\end{tabular}

Note: SS $=$ Sum of Squares, MS= Mean Square, Significance * $P<0.05$

According to Table 2, F index for the group effect $(\mathrm{F}=79.42)$ with the degree of freedom $(\mathrm{df}=1,43)$ is statistically significant. As a result, it might surely be concluded that there is statistically significant difference between two groups in terms of the method of instruction (problem-solving and traditional) $(P<0.05)$ while taking intelligence effect and creativity pre-test as the control variables.

Additionally, $\mathrm{F}$ indices for the creativity pre-test $(\mathrm{F}=26.18)$ and intelligence $(\mathrm{F}=32.18)$ with the degrees of freedom $(\mathrm{df}=1,43)$ are statistically significant. In other words, both variables made an impact on the creativity posttest scores and controlling them resulted in a significant difference between two groups' creativity in the posttest.

As Table 1 indicates, the mean value for the group provided with the problem-solving method of instruction is higher than the one for the group provided with the traditional method of instruction.

2. How will the problem-solving method of instruction influence the creativity factors (fluency, flexibility, originality, and elaboration)? In order to examine these factors between two groups under the study, covariance analysis was applied (See Table 3).

Table 3. A summary of covariance analysis for the post-test scores of the components of creativity while removing the influence of intelligence and pre-test

\begin{tabular}{|c|c|c|c|c|c|}
\hline Resources & SS & $\mathrm{DF}$ & MS & $\mathrm{F}$ & P-value \\
\hline \multicolumn{6}{|c|}{ Fluency } \\
\hline Fluency Pre-test & 104.71 & 1 & 104.71 & 62.32 & .01 \\
\hline Intelligence & 2.94 & 1 & 2.94 & 1.75 & .12 \\
\hline Group & 53.17 & 1 & 53.17 & 31.64 & .01 \\
\hline Error & 72.25 & 43 & 1.68 & & \\
\hline \multicolumn{6}{|c|}{ Flexibility } \\
\hline Flexibility Pre-test & 98.93 & 1 & 98.93 & 55.489 & .02 \\
\hline Intelligence & 5.65 & 1 & 5.65 & 3.19 & .08 \\
\hline Group & 56.21 & 1 & 56.21 & 31.75 & .02 \\
\hline Error & 76.11 & 43 & 1.77 & & \\
\hline \multicolumn{6}{|c|}{ Originality } \\
\hline Originality Pre-test & 101.63 & 1 & 101.63 & 48.62 & .01 \\
\hline Intelligence & 2.14 & 1 & 2.14 & 1.02 & .25 \\
\hline Group & 49.26 & 1 & 49.26 & 23.56 & .01 \\
\hline Error & 89.88 & 43 & 2.09 & & \\
\hline \multicolumn{6}{|c|}{ Elaboration } \\
\hline Elaboration Pre-test & 386.89 & 1 & 386.89 & 82.84 & .02 \\
\hline Intelligence & 34.15 & 1 & 34.15 & 6.27 & .01 \\
\hline Group & 490.52 & 1 & 490.52 & 105.03 & .01 \\
\hline Error & 229.17 & 43 & 4.67 & & \\
\hline
\end{tabular}

Note: $\mathrm{SS}=$ Sum of Squares, MS $=$ Mean Square, Significance ${ }^{*} P<0.05$

As Table 3 shows, $F$ index for the group effect $(\mathrm{F}=31.64)$ with the degrees of freedom $(\mathrm{df}=1,43)$ is statistically significant for the fluency. Hence, it might be inferred that there is statistically significant difference among two groups' fluency scores in terms of the method of instruction (problem-solving and traditional) $(P<0.05)$ while taking intelligence effect and fluency pre-test as the control variables. According to Table 1, the mean value for the fluency for the group provided with problem-solving method of instruction is higher than that of the group provided with the traditional method of instruction.

Moreover, Table 3 demonstrates that $\mathrm{F}$ index for the group effect $(\mathrm{F}=31.75)$ with the degrees of freedom $(\mathrm{df}=1,43)$ is 
statistically significant for the flexibility. Hence, it might be said that there is statistically significant difference among two groups' flexibility scores in terms of the method of instruction (problem-solving and traditional) $(P<0.05)$ while taking intelligence effect and fluency pre-test as the control variables. According to Table 1, the mean value for the flexibility for the group provided with problem-solving method of instruction is higher than that of the group provided with the traditional method of instruction.

Likewise, $\mathrm{F}$ index for the group effect $(\mathrm{F}=23.56)$ with the degrees of freedom $(\mathrm{df}=1,43)$ is statistically significant for the originality. According to Table 1, the mean value for the originality for the group provided with problem-solving method of instruction is higher than that of the group provided with the traditional method of instruction.

Similarly, F index for the group effect $(\mathrm{F}=105.03)$ with the degrees of freedom $(\mathrm{df}=1,43)$ is statistically significant for the elaboration. According to Table 1, the mean value for the elaboration for the group provided with problem-solving method of instruction is higher than that of the group provided with the traditional method of instruction.

\section{Discussion}

The current study aimed at investigating the possible impact of problem-solving and traditional method of instruction of math on exceptional students' creativity while the effect of intelligence on male students was controlled. In general, the findings showed that providing instruction through problem-solving method compared with traditional method would result in an increase in the exceptional students' creativity. As a result, those exceptional students who were provided with math instruction through problem-solving method gained higher scores in creativity test compared with their counterparts in the group provided with the traditional method of instruction. A plethora of theoretical and practical principles can be pinpointed to explain the obtained results.

The factor which plays a key role in the relationship between problem-solving method of instruction and creativity is the positive attitude, (i.e., interest and motivation) which is achieved through applying this method (Barak \& Mesika, 2007). The problem solving method of instruction provides the students with an opportunity to actively cooperate in the process of instruction, and to discuss and criticize each other's opinions (Kandemir \& Gür, 2009). It also encourages the students not to be confined to a single way to respond to a problem (Barak \& Mesika, 2007). In this way, it would hopefully lead to a positive attitude, and increased interest and motivation (Kandemir \& Gür, 2009). Moreover, it plays an impressive role for the exceptional students since one of the main problems in providing them with instruction is their lack of interest and motivation (Adams, Stoneham, \& Coughtrey, 2009). Providing instruction through problem-solving method and an increase in the students' interest and motivation and building a positive attitude would bring about an increase in their creativity (Barak \& Mesika, 2007). On the other hand, it seems that providing instruction through traditional method would cause lower interest and motivation among the students due to lack of sufficient cooperation of the students in the process of instruction and teacher-centeredness (Johnson, Aragon, \& Shaik, 2000).

Another variable which contributes to an increase in the exceptional students' creativity scores through problem-solving method of instruction is the extent of their active participation in the process of instruction (Adams Stoneham, \& Coughtrey, 2009). In this method, the teacher plays a less active role in the process of instruction and the students are, instead, totally involved (Kletke, 2001). Moreover, the students are actively involved in choosing the topic, searching for an answer to the problem, discussing and criticizing each other's opinions, and finally, selecting the best answer. In all these stages, the teacher plays the role of a guide and only intervenes when the students are confronted with a problem (Tennyson \& Breuer, 2002). Clement maintains that this method puts the main burden on the students and thereby, results in more sense of responsibility to accept their role in and responsibility for their success and failure (Barak \& Mesika, 2007). It also avoids their inactivity in the face of problems and helps them to seek for more innovative and diverse solutions. Accordingly, it hopefully promotes their creative thinking (Tennyson \& Breuer, 2002). Contrarily, in the traditional method of instruction, the students play the role of a mere listener and are less involved in the process of instruction. In this way, the teacher gives lectures and the students participate in the class discussion less and thereby, develop a poor sense of responsibility (Shokoohi, Parand, \& Ahmadi, 2011)

The results of the study also point to an increase in such characteristics as fluency, flexibility, originality, and elaboration through problem-solving method of instruction. To justify this issue, we should take heed of a number of factors.

An increase in the fluency score through problem-solving method of instruction might be attributed to the significance of creating several thoughts within a specific time span (Treffinger, Selby, \& Isaksen, 2008). Considering the fact that the second stage in the problem-solving pattern is planning for the problem, the main point is making the students provide various solutions for a problem. Indeed, the students should determine several solutions in a specific time span without paying attention to their accuracy (Polya, 1957). This persuades the students to seek for a number of solutions while confronting with different problems so that they choose another solution in the case of wrong ones (Palmon,\& 
Illies, 2004). Whereas creating a number of solutions within a specific time span is one of the major stages of problem-solving method of instruction (Kadivar, 2009). it seems that the traditional method of instruction leads the students to create several thoughts within a specified time with less goal-oriented approach.

An increase in the flexibility and originality through problem-solving method of instruction might also root in the opportunity which is here provided to learn how to solve a problem and use previous background knowledge in new situations and how to increase their control over the environment (Mumford, 2001). It seems that one of the problems with which the exceptional students are confronted is lack of information and skill in problem-solving. This group of students avoids facing the problems due to their lack of information and skill for solving them (Adams, Stoneham, \& Coughtrey, 2009). The problem-solving method of instruction puts a high emphasis on systematic stages of learning and helps them to apply a set of specific methods and techniques to solve the problem (Adams, Stoneham, \& Coughtrey, 2009; Polya, 1957). This method also teaches the students how to make use of their previous background knowledge in new situations (Treffinger, Selby, \& Isaksen, 2008). As a result, these students feel more confident in controlling their environment and utilizing various innovative solutions while confronting with a problem (Anne, 2002). On the contrary traditional method puts higher emphasis on the teacher's lecture and provides no opportunity to teach problem-solving skills and to apply previous background knowledge and skill for solving new problems (Prsaud, 2007; Johnson, Aragon, $\&$ Shaik, 2000) Due to their mental and physical disabilities, exceptional students cannot learn a skill through an abstract approach and need more practice and repetition in order to learn and use a skill. This seems not to be possible through a traditional method of instruction. However, it can be offered through a problem-solving method of instruction (Anne, 2002; Adams, Stoneham, \& Coughtrey, 2009).

An increase in the elaboration factor through problem-solving method of instruction might also be attributed to the emphasis this method puts on several dimensions of the problem and its analysis by presenting various solutions (Tennyson \& Breuer, 2002) According to the stages of the problem-solving pattern, understanding the problem and knowing its different dimensions and analyzing it are considered inevitable (Adams, Stoneham, \& Coughtrey, 2009).

To conclude, it might be said that employing this method draws the students' attention to the details of the problem in order to analyze it regarding several dimensions. Moreover, putting an emphasis on presenting various solutions by the students reiterates the significance of paying attention to the problem details (Barak \& Mesika, 2007; Treffinger, Selby, \& Isaksen, 2008) Contrarily, it seems that the traditional method of instruction emphasizes on the teacher's lecture and pays less attention to the problem details. It provides the students with fewer opportunities for discussing about the details of a problem. Moreover, it puts no emphasis on presenting various innovative solutions (Fatemi, Hamidi, \& Rahimi, 2011).

\section{Conclusion}

To put in the nutshell, it can be said that one of the main goals of any educational organization should be bringing up creative people in order to enable them to make right decisions in unexpected events. Exceptional students, due to several physical and mental problems, are more in need of such an approach. They need more abstract and creative thinking so that they can better tackle their problems. This seems no to be possible through the traditional method of instruction. Hence, employing innovative and creative techniques and methods in an educational system is a must. In general, the findings of the current study lend support for the positive contribution of the problem-solving method of instruction to the students' creativity score through building a positive attitude, increasing the interest and motivation, promoting the exceptional students' cooperation in the learning process, enhancing their knowledge and teaching the problem-solving skill. It is the hope of the researcher that the teachers in the exceptional students' schools set the scene for enhancing the students' creativity by acquiring and employing this method.

\section{Acknowledgments}

We are particularly grateful to Professor Parvin Kadivar for her meticulous comments and guidance in conducting this research. We should also like to thank the Education Organization for providing us the opportunity to carry out the research in schools.

\section{References}

Adams, C. S, Stoneham, A. E., \& Coughtrey, E. (2009). The role of schizotypy and creativity in a group problem-solving task. Personality and Individual Differences, 46(8), 827-831.

Anne, H. (2002). Teacher's attitudes toward the international of disabled student in to their classrooms. Teaching Exceptional Children, 3(45), 95-110.

Armagan, F. O., Sagır, A. U, \& Çelik, A. Y. (2009). The effects of students' problem solving skills on their understanding of chemical rate and their achievement on this issue. Procedia Social and Behavioral Sciences, 1 , 2678-2684. 
Barak, M., \& Mesika, P. (2007). Teaching methods for inventive problem-solving in junior high school. Thinking skills and creativity, 2, 19-29.

Batey, M., Furnham, A., \& Safiullina, X. (2010). Intelligence. general knowledge and personality as predictors of creativity. Learning and individual differences, 20, 532-535.

Conti, R., Collins, M. A., Picariello, M. L. (2001). The impact of competition on intrinsic motivation and creativity: considering, gender, gender segregation and gender role orientation. Personality and individual differences, 30, 1273-1289.

Eshrati Fard, A., Asgary, A., Sarami, G. R., Zarekar, A. (2014). A Comparative Study of the Effect of Computer-based Instruction and Problem-solving Instruction on the Students' Creativity. Journal of Education and Training Studies, 2(2), 105-113.

Fatemi, M., Hamidi, F., \& Rahimi, M. (2011). The comparative effect of computer-aided instruction and traditional teaching on student's creativity I math classes. Procedia Computer Science, 3, 266-270

Furnham, A., \& Bachtiar, V. (2008). Personality and intelligence as predictors of creativity. Personality and Individual Differences, 45, 613-617.

Furnham, A., Batey, M., Anand, K., \& Manfield, J. (2008). Personality, hypomania, intelligence and creativity. Personality and Individual Differences, 44, 1060-1069.

Geoffrey, F. M, \& Ilanit, R. T. (2007). Schizotypy versus openness and intelligence as predictors of creativity. Schizophrenia Research, 93(3), 317-324.

Guilford, J. P. (1977). Way beyond the IQ: Guide to improving intelligence and creativity. Buffalo, NY: Bearly Limited.

Helfman, J. (1992). Inventive mind: Creativity in technology. NewYork; Oxford University Press.

Jackson, L. A., Witt, E. A., Games, A. I., Fitzgerald, H. E., Eye, A. V., \& Zhao, Y. (2012). Information technology use and creativity: finding s from the children and technology project. Computers in human behavior, 28, 370-376.

Johnson, S., Aragon, S., \& Shaik, N. (2000). Comparative Analysis of Learner Satisfaction and Learning Outcomes in Online and Face-to-Face Learning Environments. Journal of Interactive Learning Research, 11, 29-49.

Kadivar, P. (2009). The Learning Psychology. SAMT: Tehran.

Kandemir, M. A, \& Gür, A. (2009). The use of creative problem solving scenarios in mathematics education: views of some prospective teachers. Procedia Social and Behavioral Sciences, 1, 1628-1635.

Kletke, M. G. (2001). Creativity in the organization: the role of individual creative problem solving and computer support. Human-computer studies, 55, 217-237.

Kyaga, S., Landén, M., Boman, M., Hultman, C. M., Langstrom, N., \& Lichtenstein, P. (2008). Mental illness, suicide and creativity: 40-Year prospective total population study Original Research Article. Journal of Psychiatric Research, 47(1), 83-90.

Mumford, M. D. (2001). Something old, something new: Revisiting Guilford's conception of creative problem solving. Creativity Research Journal, 13, 267-276.

Palmon, R. R., \& Illies, B. J. (2004). Leadership and creativity: Understanding leadership from creative problem-solving perspective. The Leadership Quarterly, 15, 55-77.

Pind, J., Gunnarsdottir, E. K. \& Johannesson, H. S. (2003). Raven's Standard Progressive Matrices: new school age norms and a study of the test's validity. Personality and Individual Differences, 34, 375-386.

Polya, G. (1957). How to solve it: A new aspect of mathematical method (2nd ed.). Princeton, NJ: Princeton University Press.

Prsaud, R. (2007). Why teaching creativity requires more than just producing more creativity. Thinking skills and creativity, 2, 68-69.

Raven, J. C. (1958). Standard Progressive Matrices. London: H.K. Lewis.

Runco, M. A. (2007). To understand is to create: An epistemological perspective on human nature and personal creativity. In R. Richards (Ed.), Everyday creativity and new views of human nature: Psychological, social, and spiritual perspectives (pp. 91-107). Washington, DC: American Psychological Association.

Samkhanian, M. R. (2008). Innovation and Creativity in the Educational. Organization.Rasane Takhasosi: Tehran.

Santrock, J. W. (2011). Educational Psychology. New York; Published by Mc Graw-Hill Companies. 
Schweizer, K., Goldhammer, F., Rauch, W., Moosbrugger, H. (2007). On the validity of Raven's matrices test: Does spatial ability contribute to performance? Personality and Individual Differences, 43, 1998-2010.

Seif, A. A. (2008). The Psychology of Innovative Growth. Doran: Tehran.

Shokoohi, M, Parand, A., \& Ahmadi, A. (2011). Effects of teaching problem solving strategies to parents of pre-teens: a study of family relationship. Procedia Social and Behavioral Sciences, 15, 957-960.

Stojanovaa, B. (2010). Development of creativity as a basic task of the modern educational system. Procedia Social and Behavioral Sciences, 2, 3395-3400.

Tennyson, R. D., \& Breuer, K. (2002). Improving problem solving and creativity through use of complex-dynamic simulations. Computers in Human Behavior, 18, 650-668.

Treffinger, D. J., Selby, E. C, \& Isaksen. (2008). Understanding individual problem-solving style: A key to learning applying creative problem solving. Learning and Individual Differences, 18, 390 - 401.

Torrance, E. P. (1974). Norms-Technical Manual Torrance test of creative thinking. Verbal Test Forms A and B. Figural test Forms $A$ and $B$. personal press Inc.

Torrance, E. P. (1990). Torrance tests of creative thinking: Manual for scoring and interpreting results(Verbal Forms A and B). Bensenville, IL: Scholastic Testing Service.

Williams, J. E., \& Mccord, D. M. (2006). Equivalence of standard and computerized versions of the Raven Progres sive Matrices Test. Computers in Human Behavior, 22, 791-800.

\section{(c)) EY}

This work is licensed under a Creative Commons Attribution 3.0 License. 